\title{
Degradação do solo e pecuária extensiva no norte de Mato Grosso
}

\author{
Anderson LANGE $^{1 *}$, Jeferson DANTAS ${ }^{2}$, Onã da Silva FREDDI ${ }^{1}$, \\ Willian BURATTO ${ }^{1}$, Cassiano SPAZIANI ${ }^{1}$, Gustavo CAIONE $^{3}$ \\ ${ }^{1}$ Instituto de Ciências Agrárias e Ambientais, Universidade Federal de Mato Grosso, Sinop, MT, Brasil. \\ ${ }^{2}$ Casa do Adubo, Cuiabá, MT, Brasil. \\ ${ }^{3}$ Universidade do Estado de Mato Grosso, Alta Floresta, MT, Brasil. \\ *E-mail: paranalange@hotmail.com
}

Recebido em junho/2018; Aceito em julho/2019.

RESUMO: A pecuária no Brasil tem uma longa história referente ao manejo de pastagens, contudo, informações sobre as alterações nas propriedades do solo devido a conversão de áreas de floresta para pastagens no bioma Amazônico ainda são incipientes. Objetivou-se mensurar os impactos nas propriedades químicas e físicas em um Latossolo Vermelho-Amarelo cultivado com pastagem por 10 e 20 anos sem correções em comparação a condição de floresta. A conversão do uso do solo de floresta para pastagens, num período de 20 anos, resultou em redução do $\mathrm{pH}$, dos teores de fósforo, potássio, cálcio, magnésio, saturação por bases e capacidade de troca catiônica. Não se verificou mudanças significativas nos estoques de carbono do solo. O uso do solo por 10 ou 20 anos com pastagem resultou em aumento da densidade de solo, causando compactação superficial.

Palavras-chave: fertilidade do solo; sustentabilidade agrícola; estoque de carbono.

\section{Soil degradation by the extensive livestock in the southern amazon of the state of Mato Grosso}

\begin{abstract}
Cattle breeding in Brazil has a long history of pasture management, however, information on changes in soil properties due to the conversion of forest areas to pasture in the Amazon biome is still incipient. The objective of this study was to measure the impacts on the chemical and physical properties of a Yellow-Red Latosol cultivated with pasture for 10 and 20 years without corrections in comparison to the forest condition. The conversion of forest land use to pasture over a 20 -year period resulted in reduced $\mathrm{pH}$, phosphorus, potassium, calcium, magnesium, base saturation, and cation exchange capacity. There were no significant changes in soil carbon stocks. Soil use for 10 or 20 years with pasture resulted in increased soil density, causing surface compaction.
\end{abstract}

Keywords: soil fertility; agricultural sustainability; carbon stock.

\section{INTRODUÇÃO}

Em áreas recém desmatadas na Amazônia o principal uso e ocupação dos solos foi e ainda é, na maioria dos casos, a pecuária, sendo caracterizada pelo rebanho extensivo, tendo como fonte principal de alimento para os animais a pastagem, que em geral, vem se degradando ao longo do tempo, devido a fatores como a escolha inadequada da espécie para cultivo, falta de correção e adubação, ausência de rodízio de piquetes, taxa de lotação inadequada, entre outros.

No estado de Mato Grosso a pecuária extensiva é uma das principais atividades econômicas, realizada basicamente sob pastejo direto de forrageiras tropicais ocupando 25,8 milhões de hectares no Estado (IMEA, 2011), grande parte na Amazônia Meridional.

A degradação de pastagens está presente em todas as regiões brasileiras, porém o problema se agrava em locais onde a pecuária vem apresentando as maiores taxas de expansão, isto é, nas áreas de fronteira agrícola (DIAS-FILHO, 2014). Na região Norte do Brasil, nos solos amazônicos, $70 \%$ das pastagens têm alto grau de degradação, com menos de 0,4 unidade animal por hectare (UA/ha) e as melhores taxas de ocupação nessa região não ultrapassam 1,9 UA/ha, o que ocorre em apenas $2 \%$ da área (DIEESE, 2011). A derrubada e queima da floresta para introdução de pastagens provoca a ruptura do "estado de equilíbrio original" com consequências negativas em relação ao sistema solo (CERRI et al., 1991). Por outro lado, a intervenção química no solo por meio da aplicação de calcário e fertilizantes em áreas de pastagem degradada pode aumentar em até sete vezes a produtividade final do capim (VOLPE et al., 2008).

Pastagens degradadas têm um impacto negativo sobre o meio ambiente que, além dos reflexos econômicos, como a perda da produtividade e da qualidade da forragem, resultam em baixa capacidade de lotação animal. Carvalho et al. (2010) em trabalho sobre a conversão da vegetação nativa em pastagem verificaram que a implantação da pastagem em solos pouco férteis como os tropicais, resulta em perdas de solo, redução nos estoques de carbono e aumento da densidade, causando degradação do solo.

Os problemas advindos da compactação não são apenas físicos, os microrganimos do solo também são afetados pela deficiência do oxigênio, alterando a decomposição do material orgânico, assim como na absorção de nutrientes pelas raízes. A queda de vigor e disponibilidade de forragem pode ser fruto do esgotamento de fósforo, nitrogênio e potássio, que foram exportados da pastagem através de produtos animais e pela ação do tempo (TOWNSEND et al., 2001). Estima-se que a produtividade de pastagens degradadas pode ser até seis vezes 
menor do que uma pastagem reformada ou em boas condições de pastejo (MACEDO et. al., 2000).

A redução da fertilidade dos solos cultivados com pastagens tem sido abordada em diversos trabalhos na literatura (DRUDI; BRAGA, 1990; SOUZA FILHO et al., 1991; SERRÃO; TOLEDO, 1994; VEIGA, 1995). Contudo, tal assunto é pouco explorado em áreas de conversão de floresta para pastagens no bioma Amazônico, definindo os impactos da substituição da vegetação natural nos ciclos biogeoquímicos do carbono, que segundo Petter et al. (2018) podem ser mais intensos neste bioma quando comparado ao bioma Cerrado. Segundo os autores isso é devido ao maior aporte anual de material vegetal via queda de serrapilheira em solos da floresta Amazônica quando comparados com as do Cerrado.

Nesse contexto, objetivou-se com o estudo mensurar os impactos na qualidade química, física e estoques de carbono de um Latossolo Vermelho-Amarelo cultivado com pastagem por 10 e 20 anos comparados a vegetação natural no bioma Amazônico.

\section{MATERIAL E MÉTODOS}

O experimento foi desenvolvido na Estância Tiradentes, localizada a $20 \mathrm{~km}$ do de Alta Floresta, no extremo Norte do estado de Mato Grosso, com localização geográfica de 55 30' a $57^{\circ} 00^{\prime}$ longitude $\mathrm{W}$ e $9^{\circ} 00^{\prime} \mathrm{e} 11^{\circ} 00^{\prime}$ latitude $\mathrm{S}$. As avaliações foram realizadas no período compreendido entre agosto de 2007 a julho de 2008.

Os tratamentos foram definidos em função do tempo de conversão da vegetação natural em pastagens. Assim os tratamentos foram estabelecidos em pastagens com 10 anos, 20 anos e área de preservação com vegetal natural, sendo todas dentro de uma propriedade rural, conduzida e manejada sempre pelo produtor. As áreas de pastagens possuíam 15 ha cada.

No momento do estabelecimento das áreas de pastagens utilizou-se a Brachiaria brizantha cv. Marandu, que foi semeada e incorporada por meio de uma grade leve, sem correção ou adubação. O produtor não realizou intervenção química ou física nas áreas desde o momento da implantação das pastagens até as avaliações.

Em cada tratamento foram estabelecidas 5 parcelas de 1 hectare cada, sendo definidas como repetições.

Para determinação das propriedades químicas do solo $(\mathrm{pH}$, $\mathrm{P}, \mathrm{K}, \mathrm{Ca}, \mathrm{Mg}, \mathrm{Al}, \mathrm{H}, \mathrm{M} . \mathrm{O}$.), foram coletados por meio de um trado holandês 5 amostras compostas nas camadas de 0 a 20 $\mathrm{cm}$ e 20 a $40 \mathrm{~cm}$. Cada amostra composta foi estabelecida pela mistura de 5 amostras simples.

$\mathrm{Na}$ mesma ocasião, foram abertas 5 trincheiras por tratamento até a profundidade de $40 \mathrm{~cm}$, coletando-se amostras indeformadas por meio de cilindros para determinação da densidade do solo. As camadas de amostragem foram de 0 a 20 e 20 a $40 \mathrm{~cm}$, retirando-se uma amostra por camada. As análises físicas e químicas de solo seguiram os métodos padrões preconizados por Embrapa (1997) e Silva (1999). Os teores de matéria orgânica do solo (MOS) foram utilizados em conjunto com a densidade do solo (DS) para calcular os estoques de carbono do solo, segundo proposto por Fernandes; Fernandes (2008).

Como a área de estudo foi considerada homogênea e as amostras coletadas dentre de cada tratamento independentes (repetições), conforme descrito em Cecagno et al. (2016), adotou-se o delineamento inteiramente casualizado para a análise de variância. Quando o teste $\mathrm{F}$ foi significativo realizou-se a comparação de médias pelo teste de Scott Knott a $5 \%$ de probabilidade.

\section{RESULTADOS}

A área amostrada era fisicamente homogênea sem grandes variações de solo, informação que se justifica pela proximidade física dos talhões e dos teores de argila que pouco variam, com 574, 553 e $559 \mathrm{~g} \mathrm{~kg}^{-1}$ na camada superficial para mata nativa, pastagem com 10 e 20 anos, respectivamente. Com a introdução da pastagem e o uso do solo por 20 anos, sem a adoção de práticas de correção e fertilização houve efeito significativo para a maioria das variáveis. Com relação a mata o solo submetido a 20 anos de pastagem apresentou reduções no de $\mathrm{pH}_{\mathrm{H} 2 \mathrm{O}}$ de 6,22 para 5,66 na camada superficial, e de 6,00 para 5,70 na subsuperfície (Figura 1).

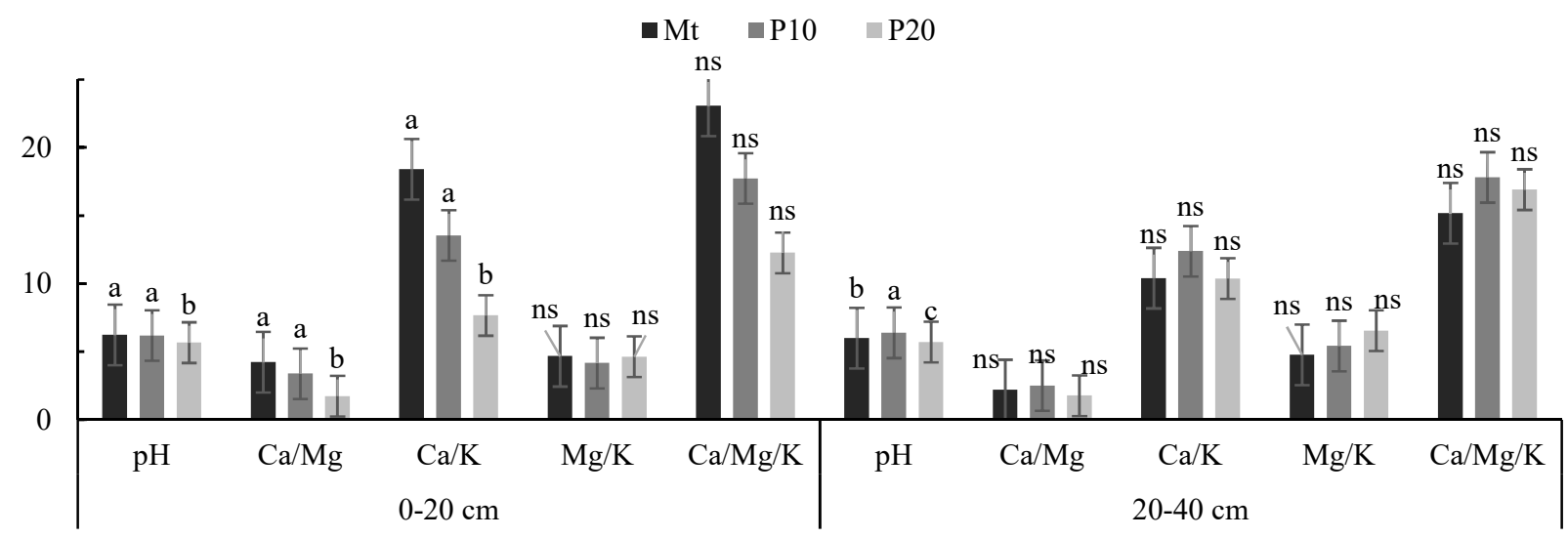

Figura 1. Variações no $\mathrm{pH}$ em água e nas relações entre as bases cálcio, magnésio e potássio no solo para as profundidades de 0-20 cm e 20$40 \mathrm{~cm}$ nos sistema de uso mata nativa (Mt), pastagem com 10 anos de uso (P10) e pastagem com 20 anos de uso (P20) em solo da Amazônia Meridional na região de Alta Floresta - MT. Médias seguidas de mesma letra não diferem entre si para os usos do solo pelo teste de Scott Knott a 5\% de probabilidade; ns - não significativo.

Figure 1. Variations in $\mathrm{pH}$ in water and in the relationships between the calcium, magnesium and potassium bases in the soil for the $0-20 \mathrm{~cm}$ and 20-40 cm depths in the system of native forest use (Mt), pasture with 10 years of use (P10) and pasture with 20 years of use (P20) in soil of Southern Amazonia in the region of Alta Floresta - MT. Averages followed by the same letter do not differ from one another for soil use by the Scott Knott test at 5\% probability; ns - not significant. 
O alumínio trocável praticamente não foi encontrado no solo, assim como sua saturação apresentou valores próximos a zero. A acidificação ficou evidente com o aumento da saturação por $\mathrm{H}$ na capacidade de troca catiônica potencial (CTC) do solo, em que o $\mathrm{H}$ ocupou mais espaço na CTC, reduzindo a saturação por bases na CTC (Figura 2). Com o tempo de uso do solo, na profundidade de 0 a $20 \mathrm{~cm}$, para 20 anos de uso com pastagem, o $\mathrm{H}$ passou a ocupar $62 \%$ de CTC contra apenas $26 \%$ quando o solo era ocupado por Mata Nativa. Na profundidade de 20 a $40 \mathrm{~cm}$, o comportamento foi semelhante, com elevação na saturação por $\mathrm{H}$ de $32 \%$ para $64 \%$ após 20 anos de uso do solo.

Os teores de fósforo $(\mathrm{P})$ que naturalmente já são baixos na região, próximos a $1,0 \mathrm{mg} \mathrm{dm}^{-3}$ ou menores (Caione et al., 2011; Lange et al., 2016) também foram reduzidos com o tempo de uso do solo pela pastagem (Figura 3). Na camada superficial decresceram de $1,56 \mathrm{mg} \mathrm{dm}^{-3}$ para $0,7 \mathrm{mg} \mathrm{dm}^{-3}$, após 20 anos de uso do solo e, em subsuperfície houve efeito significativo do uso solo, com redução de $0,7 \mathrm{mg} \mathrm{dm}^{-3}$ para $0,16 \mathrm{mg} \mathrm{dm}^{-3}$,

Ao longo do tempo de uso do solo os valores de potássio (K) foram reduzidos significativamente na camada superficial em $50 \%$ do valor original relativamente a Mata Nativa, passando de $110 \mathrm{mg} \mathrm{dm}^{-3}$ para $59 \mathrm{mg} \mathrm{dm}^{-3}$ na pastagem com 20 anos (Figura 3). Na profundidade de 20 a $40 \mathrm{~cm}$ a redução foi ainda maior, restando aproximadamente $35 \%$ do teor original de $\mathrm{K}$ no solo $\left(103 \mathrm{cmol}_{\mathrm{c}} \mathrm{dm}^{-3}\right.$ para $\left.36 \mathrm{cmol}_{\mathrm{c}} \mathrm{dm}^{-3}\right)$.

Para as bases cálcio (Ca) e magnésio $(\mathrm{Mg})$, mais especificamente para o $\mathrm{Ca}$, a redução foi mais acentuada quando comparado ao $\mathrm{K}$, pois na camada superficial os teores de Ca passaram de 5,03 para $1,12 \mathrm{cmol}_{\mathrm{c}} \mathrm{dm}^{-3}$, redução de $78 \%$ em relação a Mata Nativa e, em subsuperfície a redução foi de $69 \%$ em relação aos valores originais da Mata (Figura 4). Para o $\mathrm{Mg}$ a tendência foi a mesma, porém com uma magnitude menor, reduzindo de $1,31 \mathrm{cmol}_{\mathrm{c}} \mathrm{dm}^{-3}$ para $0,65 \mathrm{cmol}_{\mathrm{c}} \mathrm{dm}^{-3}$ na superfície do solo e de $1,24 \mathrm{cmol}_{\mathrm{c}} \mathrm{dm}^{-3}$ para $0,45 \mathrm{cmol}_{\mathrm{c}} \mathrm{dm}^{-3}$ em profundidade.

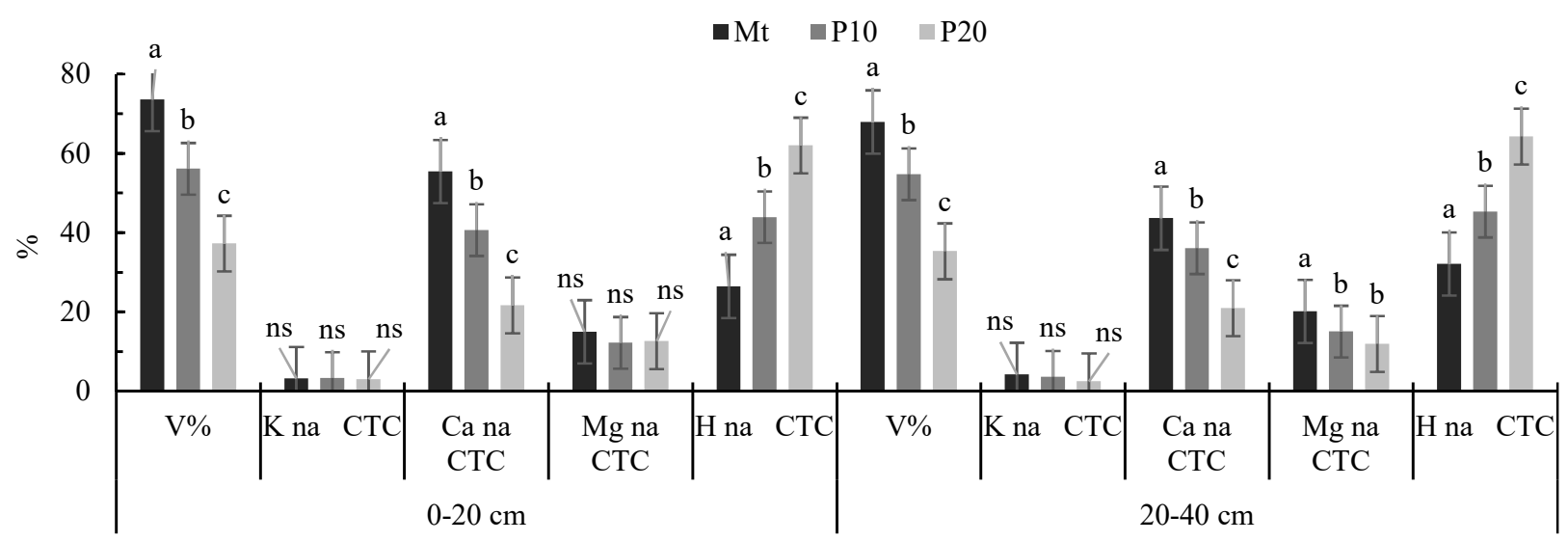

Figura 2. Variações na saturação por bases (V\%) e nas porcentagens da CTC ocupadas por potássio, cálcio, magnésio e hidrogênio no solo para as profundidades de $0-20 \mathrm{~cm}$ e $20-40 \mathrm{~cm}$ nos sistemas de uso mata nativa (Mt), pastagem com 10 anos de uso (P10) e pastagem com 20 anos de uso (P20) em solo da Amazônia Meridional na região de Alta Floresta - MT. Médias seguidas de mesma letra não diferem entre si para os usos do solo pelo teste de Scott Knott a 5\% de probabilidade; ns - não significativo.

Figure 2. Variations in base saturation (V\%) and percentages of CTC occupied by potassium, calcium, magnesium and hydrogen in the soil for the $0-20 \mathrm{~cm}$ and $20-40 \mathrm{~cm}$ depths in the native forest system (Mt), pasture with 10 years of use (P10) and pasture with 20 years of use (P20) in soil of Southern Amazonia in the region of Alta Floresta - MT. Averages followed by the same letter do not differ from one another for soil use by the Scott Knott test at 5\% probability; ns - not significant.
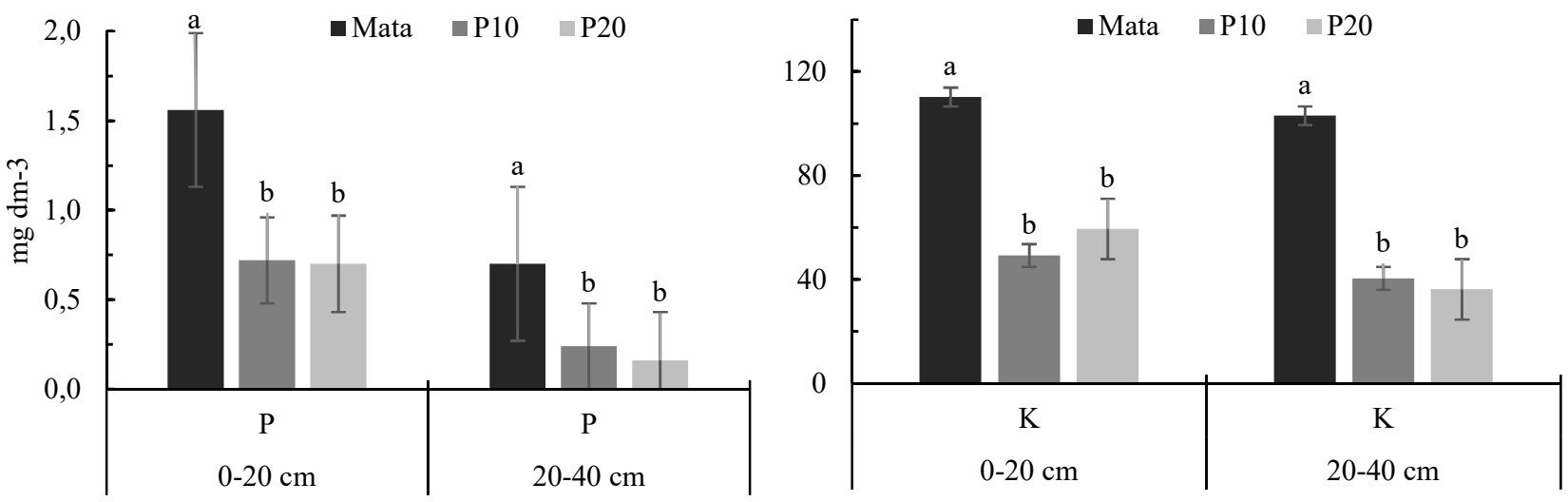

Figura 3. Variações nos teores de fósforo e potássio no solo para as profundidades de $0-20 \mathrm{~cm} \mathrm{e} 20-40 \mathrm{~cm}$ nos sistemas de uso mata nativa (M), pastagem com 10 anos de uso (P10) e pastagem com 20 anos de uso (P20) em solo da Amazônia Meridional na região de Alta Floresta - MT. Médias seguidas de mesma letra não diferem entre si para os usos do solo pelo teste de Scott Knott a 5\% de probabilidade.

Figure 3. Variations in soil phosphorus and potassium contents for the $0-20 \mathrm{~cm}$ and $20-40 \mathrm{~cm}$ depths in the native forest (Mt), pasture with 10 years of use (P10) and pasture with 20 years of use (P20) in soil of Southern Amazonia in the region of Alta Floresta - MT. Averages followed by the same letter do not differ among themselves for soil uses by the Scott Knott test at $5 \%$ probability. 


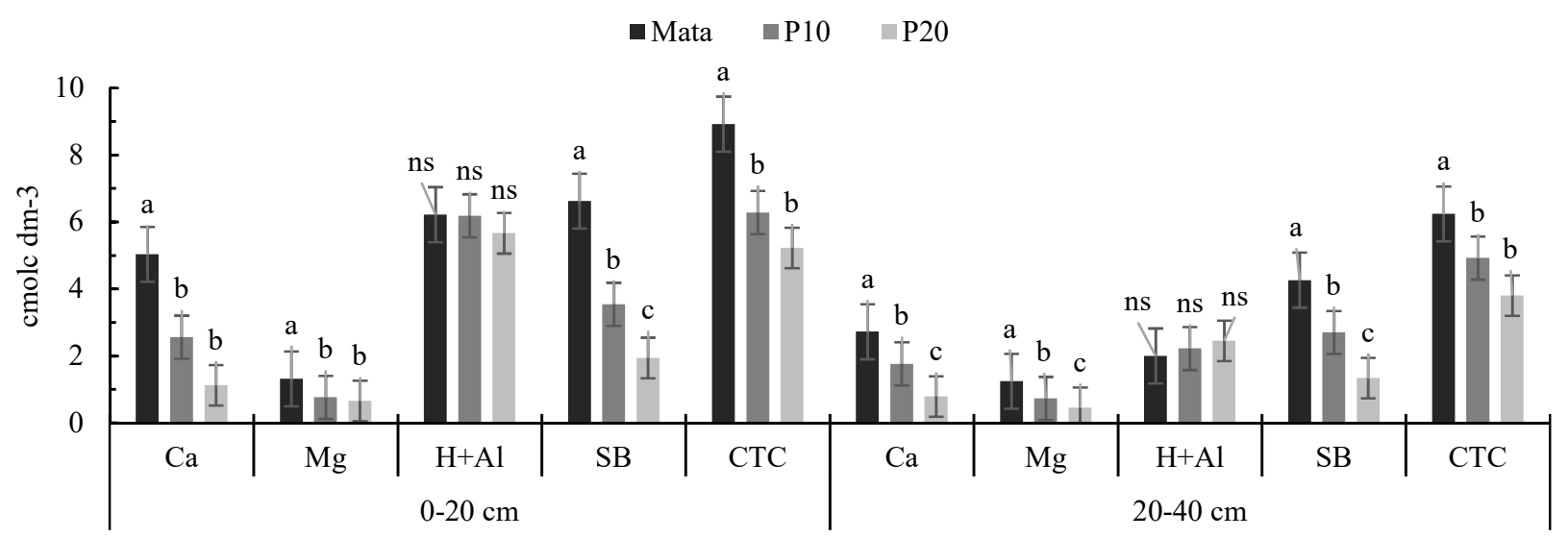

Figura 4. Variações nos teores de cálcio, magnésio, hidrogênio mais alumínio, soma de bases e capacidade de troca de cátions no solo para as profundidades de 0-20 $\mathrm{cm}$ e 20-40 cm nos sistemas de uso mata nativa (Mt), pastagem com 10 anos de uso (P10) e pastagem com 20 anos de uso (P20) em solo da Amazônia Meridional na região de Alta Floresta - MT. Médias seguidas de mesma letra não diferem entre si para os usos do solo pelo teste de Scott Knott a 5\% de probabilidade; ns - não significativo.

Figure 4. Variations in the levels of calcium, magnesium, hydrogen plus aluminum, sum of bases and capacity of exchange of cations in the soil for the depths of $0-20 \mathrm{~cm}$ and $20-40 \mathrm{~cm}$ in the system of native forest use (Mt), pasture with 10 years of use (P10) and pasture with 20 years of use (P20) in soil of Southern Amazonia in the region of Alta Floresta - MT. Averages followed by the same letter do not differ from one another for soil use by the Scott Knott test at 5\% probability; ns - not significant.

Além da redução nos valores absolutos de $\mathrm{Ca}$ e $\mathrm{Mg}$, verificou-se também redução na porcentagem de saturação destes nutrientes na CTC do solo (Figura 2). A saturação de $\mathrm{Ca}$ nas condições de Mata Nativa é de $55 \%$ e na pastagem com 20 anos é de apenas $22 \%$ na camada superficial. Na camada de 20 a $40 \mathrm{~cm}$, os valores passam de $44 \%$ para $21 \%$, sendo esta saturação preenchida por hidrogênio $(\mathrm{H})$, o que resultou em decréscimo do $\mathrm{pH}$ do solo e acidificação superficial e subsuperficial. Este resultado é respaldado pelas correlações observadas entre os valores de $\mathrm{pH}, \mathrm{Ca}$ e a porcentagem de $\mathrm{Ca}$ na CTC (Tabela 1). Verifica-se que quanto maior o $\mathrm{pH}$, maior o teor de $\mathrm{Ca}$ e as porcentagens de Ca na CTC e comportamento contrário, ou seja, quando o $\mathrm{Al}$ e o $\mathrm{H}$ começam a ocupar o complexo de troca, os teores de $\mathrm{Ca}$ e a sua saturação na CTC tendem a diminuir (Figura 2).

Em decorrência da redução nos teores de $\mathrm{Ca}, \mathrm{Mg}$ e $\mathrm{K}$ no solo, a soma de bases (SB) que na mata é de $6,62 \mathrm{cmol}_{\mathrm{c}} \mathrm{dm}^{-3}$ na camada superficial passou para apenas $1,94 \mathrm{cmol}_{\mathrm{c}} \mathrm{dm}^{-3}$ após 20 anos, configurando redução de $70 \%$, com comportamento semelhante em subsuperfície (Figura 4). O mesmo comportamento pode ser observado para a CTC do solo, com redução significativa, sendo próxima a $9 \mathrm{cmol}_{\mathrm{c}} \mathrm{dm}$ ${ }^{3}$ na camada superficial no solo sob Mata Nativa e reduzido para 5,2 $\mathrm{cmol}_{\mathrm{c}} \mathrm{dm}^{-3}$ após 20 anos de uso do solo, com comportamento semelhante para a profundidade de 20 a 40 $\mathrm{cm}$. A CTC do solo apresenta correlação direta e positiva com os teores de MO do solo (Tabela 1), ou seja, com a redução da MO a CTC também reduz. Apesar dos valores de MO não diferirem estatisticamente nos tratamentos, existe mais MO no solo de Mata Nativa, com 29,2 $\mathrm{g} \mathrm{kg}^{-1}$ na camada superficial e redução para $23,0 \mathrm{~g} \mathrm{~kg}^{-1}$ na área de pastagem com 10 anos e na pastagem com 20 anos apenas $21,60 \mathrm{~g} \mathrm{~kg}^{-1}$.

$\mathrm{Na}$ profundidade de $20 \mathrm{a} 40 \mathrm{~cm}$ também não houve diferença significativa entre os tratamentos para MO, mas há obviamente menor quantidade em comparação com a profundidade de 0 a $20 \mathrm{~cm}$ e tendência de redução nos valores com o tempo de uso do solo, pois sob Mata Nativa há $15,6 \mathrm{~g}$ $\mathrm{kg}^{-1}$ de MO e após 20 anos de uso do solo os teores reduzem para $11,6 \mathrm{~g} \mathrm{~kg}^{-1}$.
A saturação por bases (V\%) foi significativamente reduzida pelo uso do solo na forma de pastagem por 20 anos, sem a aplicação de corretivos e adubos (Figura 2). Sob Mata Nativa observa-se um V\% igual a 73,5\%, configurando um solo eutrófico, com ótimas condições para o desenvolvimento inicial da forragem. A derrubada da floresta, implantação da pastagem e o uso do solo por vários anos reduziram a $\mathrm{V} \%$ de $56 \%$ para $37 \%$, após 10 e 20 anos, respectivamente. O mesmo comportamento foi observado para a profundidade de 20 a 40 $\mathrm{cm}$, em que sob Mata Nativa o V\% era de $67 \%$, decaindo para $35 \%$ após 20 anos de uso do solo. Na condição de Mata Nativa, com $\mathrm{V} \%$ de $73 \%$, as saturações por $\mathrm{Ca}, \mathrm{Mg}$ e $\mathrm{K}$ eram de $55,4 \%$, $14,98 \%$ e $3,18 \%$, respectivamente, e após 20 anos, considerando a mesma sequência de atributos, foram observadas reduções de 21,6\%, 12,6\% e 2,96\% (Figura 2), o que certamente prejudica a nutrição da forragem e desencadeia cada vez mais o processo de degradação.

O uso do solo por 10 ou 20 anos aumentou a densidade de solo, causando compactação superficial (Figura 5), já em subsuperfície o efeito não foi significativo, apesar do aumento numérico. Em relação aos estoques de carbono, não houve efeito significativo, apesar de numericamente os valores serem muito maiores na Mata Nativa.

\section{DISCUSSÃO}

O uso do solo sem um processo de reposição de nutrientes ou práticas conservacionistas, que minimizem a erosão e lixiviação de nutrientes, gera acidificação do solo superficial e subsuperficialmente, reduzindo a qualidade da forragem (CRUZ et al., 1994).

A redução nos teores de $\mathrm{P}$ de $0,7 \mathrm{mg} \mathrm{dm}^{-3}$ para $0,16 \mathrm{mg} \mathrm{dm}^{-}$ 3 possivelmente ocorreu pela retirada deste elemento pelas raízes das plantas de braquiária, esgotamento a reserva mínima do solo para assim manter os teores de $\mathrm{P}$ na matéria verde, mantendo o crescimento da forragem até o estágio de degradação desta, já que este nutriente não está sujeito a lixiviação. Os maiores teores de P na Mata Nativa comparados a 10 ou 20 anos de pastejo são ocasionados pela menor taxa de mineralização da matéria orgânica, liberando nutrientes gradativamente ao sistema. A ausência de diferença 
significativa nos teores de $\mathrm{P}$ entre os anos de uso por pastagem se deve a baixa disponibilidade deste elemento na região e a semelhança no manejo que está sendo adotado na propriedade, sem reposição de nutrientes. Inicialmente, no estabelecimento da pastagem se perde $\mathrm{P}$ com a retirada de Mata Nativa, posteriormente mais $\mathrm{P}$ é perdido ou exportado com o passar dos anos, via pastejo e erosão, mantendo a quantidade disponível quase que inalterada.
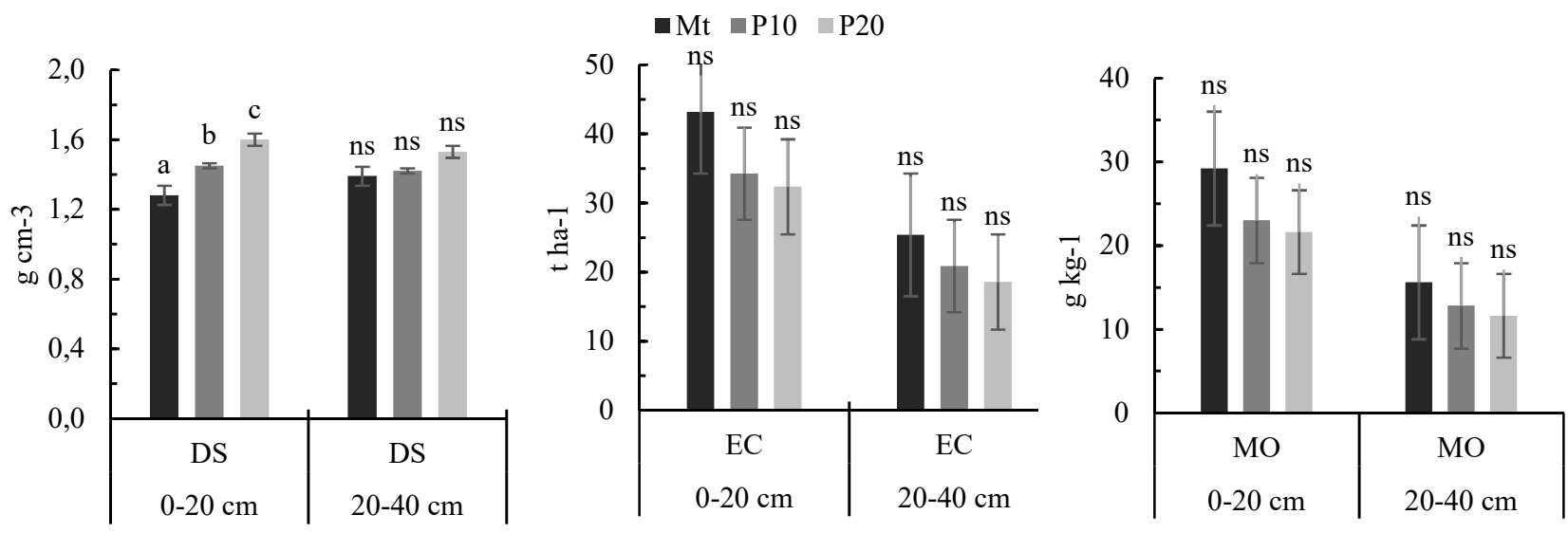

Figura 5. Variações na densidade do solo (DS), nos estoques de carbono (EC) e matéria orgânica (MO), para as profundidades de 0-20 cm e 20-40 cm nos sistema de uso mata nativa (Mt), pastagem com 10 anos de uso (P10) e pastagem com 20 anos de uso (P20) em solo da Amazônia Meridional na região de Alta Floresta - MT. Médias seguidas de mesma letra não diferem entre si para os usos do solo pelo teste de Scott Knott a 5\% de probabilidade; ns - não significativo.

Figure 5. Variations in soil density (DS), carbon (EC) and organic matter (MO), for depths of $0-20 \mathrm{~cm}$ and $20-40 \mathrm{~cm}$ in the system of native forest use (Mt), pasture with 10 years of use (P10) and pasture with 20 years of use (P20) in soil of Southern Amazonia in the region of Alta Floresta - MT. The same of the soil by test the Scottish Knights the 5\% probability; ns - not significant.

Tabela 1. Correlação de Pearson para os atributos químicos do solo nas camadas de 0-20 e 20-40 cm de profundidade para os sistemas de uso do solo Mata Nativa, pastagem com 10 e 20 anos de uso. $(*)$ correlação significativa.

Table 1. Pearson correlation for soil chemical attributes in the 0-20 and 20-40 cm depth layers for the Mata Nativa soil use systems, pasture with 10 and 20 years of use. $\left(^{*}\right)$ significant correlation.

\begin{tabular}{|c|c|c|c|c|c|c|c|c|c|c|c|c|c|c|c|}
\hline & \multicolumn{2}{|c|}{$\mathrm{pH}_{\mathrm{H} 2 \mathrm{O}} \quad \mathrm{pH}_{\mathrm{CaCl}}$} & $\mathrm{P}$ & K & $\mathrm{Ca}$ & $\mathrm{Mg}$ & $\mathrm{Al}$ & $\mathrm{H}$ & $\mathrm{MO}$ & SB & CTC & $\mathrm{V} \%$ & $\% \mathrm{~K}$ & $\% \mathrm{Ca}$ & $\% \mathrm{Mg}$ \\
\hline & 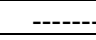 & 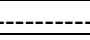 & י-י--י-בי & י-י-י-ים & י-י-י-י-ירי & יני-י-יביר. & $0 \mathrm{a} 20 \mathrm{c}$ & n----- & - & יו-י-בי- & - & 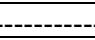 & יו-י-ניב- & & \\
\hline pHн2O & 1 & & & & & & & & & & & & & & \\
\hline $\mathrm{pH} \mathrm{HaCl}_{\mathrm{C}}$ & $0,91 *$ & 1 & & & & & & & & & & & & & \\
\hline $\mathrm{P}$ & 0,43 & $0,70^{*}$ & 1 & & & & & & & & & & & & \\
\hline $\mathrm{K}$ & $0,52 *$ & 0,48 & 0,37 & 1 & & & & & & & & & & & \\
\hline $\mathrm{Ca}$ & $0,83^{*}$ & $0,97 *$ & $0,77^{*}$ & $0,56^{*}$ & 1 & & & & & & & & & & \\
\hline $\mathrm{Mg}$ & 0,27 & 0,49 & $0,76^{*}$ & $0,65^{*}$ & $0,59 *$ & 1 & & & & & & & & & \\
\hline $\mathrm{Al}$ & $-0,59 *$ & $-0,51$ & $-0,38$ & $-0,36$ & $-0,42$ & $-0,4$ & 1 & & & & & & & & \\
\hline $\mathrm{H}$ & $-0,68^{*}$ & $-0,72 *$ & $-0,57^{*}$ & $-0,03$ & $-0,63^{*}$ & $-0,17$ & 0,47 & 1 & & & & & & & \\
\hline M.O & $0,55^{*}$ & $0,62 *$ & 0,41 & $0,68^{*}$ & $0,71^{*}$ & $0,53^{*}$ & $-0,27$ & $-0,08$ & 1 & & & & & & \\
\hline SB & $0,79^{*}$ & $0,94 *$ & $0,81^{*}$ & $0,64^{*}$ & $0,98^{*}$ & $0,70^{*}$ & $-0,44$ & $-0,57^{*}$ & $0,73^{*}$ & 1 & & & & & \\
\hline СТC & $0,67 *$ & $0,83^{*}$ & $0,73^{*}$ & $0,73^{*}$ & $0,91 *$ & $0,75^{*}$ & $-0,33$ & $-0,3$ & $0,83^{*}$ & $0,95^{*}$ & 1 & & & & \\
\hline V\% & $0,85^{*}$ & $0,95^{*}$ & $0,79 *$ & $0,56^{*}$ & $0,93 *$ & $0,66^{*}$ & $-0,63 *$ & $-0,75^{*}$ & $0,58^{*}$ & $0,94 *$ & $0,82 *$ & 1 & & & \\
\hline$\% \mathrm{~K}$ & 0,22 & 0,04 & 0,00 & $0,81^{*}$ & 0,09 & 0,28 & $-0,29$ & 0,12 & 0,31 & 0,17 & 0,23 & 0,16 & 1 & & \\
\hline$\% \mathrm{Ca}$ & $0,91 *$ & $0,99 *$ & $0,73^{*}$ & 0,48 & $0,95^{*}$ & $0,52 *$ & $-0,56^{*}$ & $-0,76^{*}$ & $0,59 *$ & $0,93 *$ & $0,81^{*}$ & $0,97 *$ & 0,08 & 1 & \\
\hline$\% \mathrm{Mg}$ & $-0,21$ & $-0,06$ & 0,42 & 0,21 & 0,09 & $0,71^{*}$ & $-0,33$ & $-0,06$ & $-0,07$ & 0,12 & 0,1 & 0,2 & 0,17 & 0,01 & 1 \\
\hline & - & 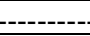 & 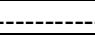 & 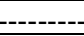 & ------י- & 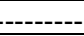 & 20 a 40 & m - - & - & ניו-יו- & ניו-יו- & - & ניו-יו-יני & & \\
\hline рНн2о & 1 & & & & & & & & & & & & & & \\
\hline $\mathrm{pH}_{\mathrm{CaCl}}$ & $0,89^{*}$ & 1 & & & & & & & & & & & & & \\
\hline $\mathrm{P}$ & 0,02 & 0,27 & 1 & & & & & & & & & & & & \\
\hline $\mathrm{K}$ & 0,39 & 0,47 & $0,52 *$ & 1 & & & & & & & & & & & \\
\hline $\mathrm{Ca}$ & 0,47 & $0,63^{*}$ & $0,78^{*}$ & $0,80^{*}$ & 1 & & & & & & & & & & \\
\hline $\mathrm{Mg}$ & 0,27 & 0,46 & $0,84^{*}$ & $0,73^{*}$ & $0,92 *$ & 1 & & & & & & & & & \\
\hline $\mathrm{Al}$ & $-0,61 *$ & $-0,73 *$ & $-0,33$ & $-0,45$ & $-0,53^{*}$ & $-0,48$ & 1 & & & & & & & & \\
\hline $\mathrm{H}$ & $-0,22$ & $-0,55^{*}$ & $-0,34$ & 0,13 & $-0,23$ & $-0,20$ & 0,50 & 1 & & & & & & & \\
\hline M.O & 0,05 & 0,10 & 0,43 & 0,48 & $0,60^{*}$ & $0,51^{*}$ & $-0,06$ & 0,36 & 1 & & & & & & \\
\hline SB & 0,43 & $0,58^{*}$ & $0,80^{*}$ & $0,83^{*}$ & $0,99 *$ & $0,95^{*}$ & $-0,52 *$ & $-0,19$ & $0,59 *$ & 1 & & & & & \\
\hline CTC & 0,35 & 0,39 & $0,68^{*}$ & $0,88^{*}$ & $0,91^{*}$ & $0,88^{*}$ & $-0,34$ & 0,15 & $0,72^{*}$ & $0,93 *$ & 1 & & & & \\
\hline V\% & $0,58^{*}$ & $0,80^{*}$ & $0,74^{*}$ & $0,66^{*}$ & $0,90^{*}$ & $0,85^{*}$ & $-0,73^{*}$ & $-0,57 *$ & 0,29 & $0,89 *$ & $0,69 *$ & 1 & & & \\
\hline$\% \mathrm{~K}$ & $0,62 *$ & $0,51^{*}$ & 0,41 & $0,91 *$ & $0,64 *$ & $0,52 *$ & $-0,53 *$ & $-0,02$ & 0,24 & $0,65^{*}$ & $0,64 *$ & $0,60^{*}$ & 1 & & \\
\hline$\% \mathrm{Ca}$ & $0,64 *$ & $0,85^{*}$ & $0,68^{*}$ & $0,63^{*}$ & $0,89^{*}$ & $0,77^{*}$ & $-0,70 *$ & $-0,58 *$ & 0,33 & $0,86^{*}$ & $0,66^{*}$ & $0,98^{*}$ & $0,59 *$ & 1 & \\
\hline$\% \mathrm{Mg}$ & 0,23 & $0,52^{*}$ & $0,74^{*}$ & 0,41 & $0,70 *$ & 0,86 & $-0,61 *$ & $-0,54 *$ & 0,13 & $0,74 *$ & $0,54^{*}$ & $0,83^{*}$ & 0,28 & $0,73^{*}$ & 1 \\
\hline
\end{tabular}

Os resultados semelhantes em relação aos teores de P para a pastagem de 10 e 20 anos são previsíveis em função do elevado teores de P no esterco, decorrente de uma alimentação dos animais com suplementação mineral rica em $\mathrm{P}$, já que os 
animais ingerem sal mineral periodicamente. Animais em pastejo ingerem mais $\mathrm{P}$ do sal mineral do que das gramíneas e, do total de sal que este animal ingere, próximo a $70 \%$ volta ao solo vias excretas (TEIXEIRA,1987). Autores que investigaram a correção e adubação do solo em gramíneas tropicais, de maneira geral, têm verificado que os teores de o $\mathrm{P}$ e $\mathrm{N}$ flutuam em função

das condições edafoclimáticas e das técnicas associadas (VILELA et al., 2004). O P é o nutriente mais citado como a principal causa da baixa produtividade das pastagens em solos ácidos de baixa fertilidade, sendo considerado o nutriente mais importante para a formação de pastagens em solos da região do Cerrado (VILELA et al., 2002).

A redução de $35 \%$ no teor de $\mathrm{K}$, pode ser explicada pela exportação do nutriente pela forragem, em que os animais consomem o pasto, exportando grandes quantidades de $\mathrm{K}$, e principalmente pela lixiviação e escorrimento superficial, pois o solo sem proteção terá uma maior velocidade escoamento superficial. Salienta-se que a condição de relevo plano a suave ondulado da região reduz o escorrimento, porém verificou-se também redução não significativa no teor de matéria orgânica e também nos estoques de carbono no solo (Figura 5), o que reduz a CTC e assim facilita a lixiviação do $\mathrm{K}$.

A redução dos teores de $\mathrm{Ca}, \mathrm{Mg}$ e $\mathrm{K}$, pode ser um índice para determinar a degradação das pastagens na região, já que estes nutrientes são essenciais em diversas atividades metabólicas das plantas como constituinte de parede celular e lamela média, estabilização das membranas celulares, ativação enzimática e composição da molécula de clorofila (MALAVOLTA et al., 1997).

Sabe-se que a forma mais barata e usual de se fornecer $\mathrm{Ca}$ e $\mathrm{Mg}$ às plantas é a calagem e diversos trabalhos mostram efeitos positivos desta correção como prática primordial para o melhor desenvolvimento das forrageiras. Costa et al. (2012), variando doses de calcário, verificaram efeito quadrático para incremento de matéria seca (MS) de B. Brizantha cv. Xaraés, após 5 cortes. Volpe et al. (2008) verificaram diferenças expressivas no ganho de MS da pastagem ao estudarem o uso de calcário e de fertilizantes para correção do solo sob pastagem.

A redução da CTC para 5,2 $\mathrm{cmol}_{\mathrm{c}} \mathrm{dm}^{-3}$ após 20 anos, devese a redução das bases no solo, pois os teores de $\mathrm{H}$ não foram afetados com o uso do solo, ficando próximos a $6 \mathrm{cmol}_{\mathrm{c}} \mathrm{dm}^{-3}$ na camada superficial e próximos a 2,0 $\mathrm{cmol}_{\mathrm{c}} \mathrm{dm}^{-3} \mathrm{em}$ profundidade, independentemente do tempo de uso do solo.

Pode-se inferir que a redução nos teores de MO provocam maior lixiviação e perda de nutrientes no perfil do solo, pela redução no complexo de troca (CTC), reduzindo os pontos de ligação dos cátions nos coloides orgânicos, o que tem correlação direta também com o pH do solo (Tabela 1), em função das cargas variáveis ou dependentes de $\mathrm{pH}$.

Os maiores teores de MO no solo para a Mata Nativa nas duas camadas ocorrem, obviamente, pela maior deposição de material orgânico (serapilheira) e pela menor taxa percentual de decomposição, pois o processo de decomposição é mais ativo quando a temperatura do solo é maior, ocorrendo uma redução no acúmulo de matéria orgânica no solo (Brady, 1989).

As relações $\mathrm{Ca} / \mathrm{Mg}, \mathrm{Ca} / \mathrm{K}$ na camada de 0 a $20 \mathrm{~cm}$ foram afetadas pelo tempo de uso do solo, com redução significativa, ocasionadas principalmente pela redução nos teores de $\mathrm{Ca}$, o que reduziu/alterou as relações (Figura 1). Na Mata Nativa a relação era de 4,22 (Ca/Mg), decaindo para 1,72 após 20 anos de uso do solo. Nesta condição é comum o bom desempenho das forragens nos primeiros anos de uso do solo porém, com o uso as condições não são mais ideais, pois sabe-se que gramíneas tropicais requerem, para um bom desenvolvimento, condições no solo de $\mathrm{Ca} / \mathrm{Mg}$ próximas a $3 / 1$ ou superiores (VITTI et al., 2006; SOUSA; LOBATO, 2004), condição mantida na Mata e na pastagem de 10 anos, sendo estatisticamente semelhantes e diferentes da pastagem de 20 anos, em que a relação $\mathrm{Ca} / \mathrm{Mg}$ é de 1,72 . Segundo Vitti et al. (2006), a Brachiaria brizantha cv. Marandu requer V\% para implantação e manutenção de 60 e 50, respectivamente e, nesta condição, manter uma saturação de $\mathrm{Ca}, \mathrm{Mg}$ e K na CTC de $35 \%, 11 \%$ e $4 \%$, respectivamente. Assim, a análise de solo na pastagem de 20 anos apresenta o V\% e a saturação de Ca na CTC é de 37 e 21,6, respectivamente, ambas abaixo do ideal. Já a saturação de K e Mg não estão baixas, o que remete a falta de Ca no sistema. A importância do Ca deve a estrutura da planta, como integrante da parede celular incrementando a resistência mecânica dos tecidos. Ele também interage com outros elementos, aumentando a absorção de potássio, amônio e fósforo e sua restrição reduz o crescimento de raízes, ramos e folhas, abundante neste último compartimento, e a deficiência ainda impede a abertura de novas folhas (TROEH; THOMPSON, 2007).

Aumento dos níveis de compactação causado pelo uso do solo, pelo pisoteio animal é documentado na literatura e regionalmente isto tem sido observado. Oliveira et al. (2015) estudando a resistência a penetração do solo em sistemas integrados e tendo a mata nativa como padrão, verificaram aumento da resistência à penetração até $25 \mathrm{~cm}$ de profundidade, sendo a área de pastagem significativamente mais compactada que áreas nativas.

\section{CONCLUSÕES}

A conversão de área de Mata Nativa para pastagem com pastejo contínuo após 20 anos reduz os teores de fósforo, potássio, cálcio, magnésio significativamente em $50 \%$ ou mais, causando acidificação do solo, redução da CTC. Algumas propriedades químicas são afetadas até $40 \mathrm{~cm}$, além do aumento da densidade do solo em superfície.

\section{REFERÊNCIAS}

BRADY, N. C. Natureza e propriedade dos solos. 7. ed. Rio de Janeiro: Freitas Bastos, 1989. 879 p.

CAIONE, G.; LANGE, A.; BENETT, C. G. S.; FERNANDES, F. M. Phosphorus sources for sugarcane forage cultivars fertilization in the Brazilian savannah. Pesquisa Agropecuária Tropical, Goiânia, v. 41, n. 1, p. 66-73, $2011 . \quad$ DOI https://dx.doi.org/10.5216/pat.v41i1.8497

CECAGNO, D.; DE ANDRADE, S. E. V. G.; ANGHINONI, I.; KUNRATH, T. R.; MARTINS, A. P.; REICHERT, J. M.; GUBIANIC, P. I.; BALERINIA, F.; FINKA, J. R.; FACCIO CARVALHO, P. C. Least limiting water range and soybean yield in a long-term, no til, integrated croplivestock systems under different grazing intensities. Soil and Tillage Research, Amsterdam, v. 156, p. 54-62, 2016. https://dx.doi.org/10.1016/j.still.2015.10.005

CARVALHO, J. L. N.; RAUCCI, G. S.; CERRI, C. E. P.; BERNOUX, M.; FEIGL, B. J.; WRUCK, F. J.; CERRI, C. C. Impact of pasture, agriculture and crop-livestock systems on soil $\mathrm{C}$ stocks in Brazil. Soil \& Tillage 
Research, Amsterdam, v. 110, n. 1, p. 175-186, 2010 DOI: https://dx.doi.org/10.1016/j.still.2010.07.011

CERRI, C. C.; MORAES, J. F. L.; VOLKOFF, B. Dinâmica do carbono orgânico em solos vinculados a pastagens na Amazônia Brasileira. Investigación Agrária, v. 1, p. 95102, 1991.

COSTA, N. L.; PAUlinO, V. T.; MAGAlHÃES, J. A.; RODRIGUES, A. N. A.; BENDAHAN, A. B.; NASCIMENTO, L. E. da S.; FERNANDES, R. C. P. Resposta de Brachiaria brizantha cv. Xaraés a níveis de calagem. PUBVET, Londrina, v. 6, 2012.

CRUZ M. C. P.; FERREIRA, M. E.; LUCHETTA, S. Efeito da calagem sobre a produção de matéria seca de três gramíneas forrageiras. Pesquisa Agropecuária Brasileira, Brasília, v. 29, n.8, p. 1303-1312, 1994.

DIAS FILHO, M. B. Diagnóstico das pastagens no Brasil. Belém: Embrapa Amazônia Oriental, 2014. 38 p. (Documentos, 402).

DIEESE. Estatísticas do meio rural 2010-2011. 4. ed. São Paulo: DIEESE: NEAD: MDA, 2011. 292 p.

DRUDI, A.; BRAGA, A. F. Níveis de fósforo, enxofre e micronutrientes na recuperação de pastagens degradadas em solos arenosos na região norte de Tocantins. Pesquisa Agropecuária Brasileira, Brasília, v. 25, n. 9, p. 13171322, 1990.

EMBRAPA EMPRESA BRASILEIRA DE PESQUISA AGROPECUÁRIA. Manual de métodos de análise de solo. 2. ed. Embrapa Solos, Rio de Janeiro, 1997. 212 p.

FERNANDES, F. A.; FERNANDES, A. H. B. M. Cálculo dos estoques de carbono do solo sob diferentes condições de manejo. Corumbá: Embrapa Pantanal, 2008. 4 p. (Comunicado Técnico, 69).

IMEA INSTITUTO MATOGROSSENSE DE ECONOMIA AGROPECUÁRIA. Relatório do levantamento sobre a morte de pastagem em Mato Grosso. Mato Grosso, 2011. Disponível

em: $<$ http://www.imea.com.br/upload/pdf/arquivos/Relatorio_ do_Levantamento_sobre_morte de pastagem em Mato Grosso.pdf>. Acesso em 16 de maio de 2018.

LANGE, A.; DIEL, D.; CARVALHO, F. F.; MACHADO, R. A. F.; ZANUZO, M. R.; SILVA, A. DA; BUCHELT, A. C. Fontes de fósforo na adubação corretiva em arroz de terras altas em cultivo de primeiro ano. Revista de Ciências Agroambientais, Alta Floresta, v. 14, n. 1, p. $67-$ 75, 2016

MACEDO, M. C. M.; KICHEL, A. N.; ZIMMER, A. H.; Degradação e alternativas de recuperação e renovação de pastagens. Campo Grande: Embrapa gado de corte, 2000. 4 p. (Comunicado Técnico, 62).

MALAVOLTA, E.; VITTI, G. C.; OLIVEIRA, A. S. Avaliação do estado nutricional das plantas: princípios e aplicações. 2. ed. Potafós: Piracicaba, 1997.319 p.

OLIVEIRA, B. S.; CARVALHO, M. A. C.; LANGE, A.; DALLACORT, R.; SILVA, V. P. Resistência do solo à penetração em áreas sob o sistema de integração lavourapecuária-floresta na região Amazônica. Enciclopédia Biosfera, Goiânia, v. 11, n. 22, p. 3678-3689, 2015.

PETTER, F. A.; LIMA, L. B.; MORAIS, L. A.; TAVANTI, R. R.; FREDDI, O. S.; MARINO JUNIOR, B. H. Carbon stocks in oxisols under agriculture and forest in the Southern Amazon of Brazil. Geoderma Regional, v. 11, p. 53-61, 2018.20 https://dx.doi.org/10.1016/j.geodrs.2017.09.001
SERRÃO, E. A. S.; TOLEDO, J. M. Sustaning pasture-based production systems for the humid tropics. In: DOWINIWG, T. E.; HECHT, S. B.; PEARSON, H. A.; GARCIA-DOWNING， C. (Ed.). Development or destruction - the conversion of tropical forest to pasture in Latin America. Boulder/San Francisco/Oxford: Westuiew Press, 1994. p. 257-280.

SILVA, F. C. Manual de análises químicas de solos, plantas e fertilizantes. Brasília: Empresa Brasileira de Pesquisa Agropecuária, 1999. $370 \mathrm{p}$.

SOUZA FILHO, A. P. S.; TEIXEIRA NETO, J. F.; VEIGA, J. B. Adubação de pastagem de capim-colonião em degradação, em Santana do Araguaia (Pará). Belém: EMBRAPA/CPATU, 1991. 16 p. (Boletim de Pesquisa, 120).

SOUSA, D. M. G.; LOBATO, E. Cerrado: correção do solo e adubação. Brasília: Embrapa Informações Tecnológicas, 2004.

TEIXEIRA, L. B. Dinâmica do ecossistema de pastagem cultivada em área de floresta na Amazônica Central. 1987. 100f. Tese (Doutorado) - Fundação Universidade do Amazonas, Manaus, 1987.

TOWNSEND, C. R.; COSTA, N. de L.; MENDES, A. M.; PEREIRA, R. de G. A.; MAGALHÃES, J. A. Nutrientes limitantes em solo de pastagens degradadas de Brachiaria brizantha cv. Marandu em Porto Velho-RO. In: REUNIÃO ANUAL DA SOCIEDADE BRASILEIRA DE ZOOTECNIA, 38., Fortaleza, 2001, Anais... Piracicaba, SBZ, 2001. p.158-159.

VEIGA, J. B. Reabilitação de áreas de pastagens degradadas. In: PARROTA, J.A. \& KANASHIRO, M. (Ed) Simpósio sobre manejo e reabilitação de áreas degradadas e florestas secundárias na Amazônia. Santarém. In: SIMPÓSIO SOBRE MANEJO E REABILITAÇÃO DE ÁREAS DEGRADADAS E FLORESTAS SECUNDÁRIAS NA AMAZÔNIA, 1993, Santarém, PA. Anais... Rio Piedras: Instituto Internacional de Floresta Tropical: USDA-Servico Florestal; Belém: EMBRAPA-CPATU, 1995. p. 191-200.

VILELA, L.; SOARES, W. V.; SOUSA, D. M. G. de; MACEDO, M. C. M. Calagem e adubação para pastagens. In: SOUSA, D. M. G. de; LOBATO, E. (Ed.). Cerrado: correção do solo e adubação. Planaltina: Embrapa Cerrados, 2002. p. 367-382.

VILELA, L.; MARTHA JR., G. B.; BARIONI, L. G. e BARCELLOS, A. O. Adubação na recuperação e na intensificação da produção animal em pastagens. In: SIMPÓSIO SOBRE O MANEJO DA PASTAGEM, 21., Piracicaba. Anais... Piracicaba: FEALQ, 2004. p.425-472.

VITTI, G. C.; LUCHIO, J. P. M. DE; CRUZ, A. DE P.; SPOLIDÓRIO, E. S. Nutrição e adubação de pastagens forrageiras. In: Wagner Pires. (Org.). Manual de pastagens: formação, manejo e recuperação. Viçosa: Aprenda Fácil, 2006, p. 199-248.

VOLPE, E.; MARCHETTI, M. E.; MACEDO, M. C. M.; ROSA JÚNIOR, E. J. Renovação de pastagem degradada com calagem, adubação e leguminosa consorciada em Neossolo Quartzarênico. Acta cientiarum. Agronomy. Maringá, v. 30, n. 1, p. 131-138, 2008. DOI: http://dx.doi.org/10.4025/actasciagron.v30i1.1162

TROEH, F. R.; THOMPSON, L. M. Solos e fertilidade do solo. São Paulo: Andrei, 2007. 718 p. 